IZA DP No. 8942

Bubble Economics and Structural Change: The Cases of Spain and France Compared

Pablo Agnese

Jana Hromcová

March 2015 


\title{
Bubble Economics and Structural Change: The Cases of Spain and France Compared
}

\author{
Pablo Agnese \\ FH Düsseldorf \\ and IZA
}

Jana Hromcová

Universitat Autònoma de Barcelona

Discussion Paper No. 8942

March 2015

IZA

P.O. Box 7240

53072 Bonn

Germany

Phone: +49-228-3894-0

Fax: +49-228-3894-180

E-mail: iza@iza.org

\begin{abstract}
Any opinions expressed here are those of the author(s) and not those of IZA. Research published in this series may include views on policy, but the institute itself takes no institutional policy positions. The IZA research network is committed to the IZA Guiding Principles of Research Integrity.

The Institute for the Study of Labor (IZA) in Bonn is a local and virtual international research center and a place of communication between science, politics and business. IZA is an independent nonprofit organization supported by Deutsche Post Foundation. The center is associated with the University of Bonn and offers a stimulating research environment through its international network, workshops and conferences, data service, project support, research visits and doctoral program. IZA engages in (i) original and internationally competitive research in all fields of labor economics, (ii) development of policy concepts, and (iii) dissemination of research results and concepts to the interested public.
\end{abstract}

IZA Discussion Papers often represent preliminary work and are circulated to encourage discussion. Citation of such a paper should account for its provisional character. A revised version may be available directly from the author. 


\section{ABSTRACT \\ Bubble Economics and Structural Change: The Cases of Spain and France Compared ${ }^{*}$}

This paper delves into the recent events that led to the formation of the housing bubble in Spain and the resulting structural change that is arguably needed to put the economy back into the right track. For this purpose we calibrate a model with different equilibria descriptive of the labor markets in Spain and France, where the unemployment rates went from the same initial spot to very different levels. In addition to this, we run two counterfactual analyses that throw some more light on the performance of the Spanish labor market and the Spanish housing bubble. Our results suggest that the unemployment rate in Spain has jumped to much higher levels while switching between equilibria or, what is the same, because of structural change. Moreover, our counterfactuals indicate that, first, the Spanish flexibilization reform has fallen short of its own goals and, second, there has been an important misdirection of resources into the construction industry mainly fueled by excessively low real interest rates.

JEL Classification: J64, O57

Keywords: $\quad$ structural change, bubble, unemployment, interest rate, productivity

Corresponding author:

Pablo Agnese

FH Düsseldorf

Department of Business Studies

Universitätsstraße Geb. 23.32

40225 Düsseldorf

Germany

E-mail: pablo.agnese@fh-duesseldorf.de

\footnotetext{
* Financial support from the Spanish Ministry of Education and Science through grant ECO201237572 is gratefully acknowledged.
} 


\section{Introduction}

In this paper we aim at finding a possible answer to the structural change that took place in Spain in recent years, as particularly manifested by the sharp increase in the unemployment rate to all-time record levels. Spain, unlike many other countries in the EU, embarked, through its banking sector, in a lending spree fueled by the ECB's lax monetary policy that ended up in the housing bubble and the subsequent deep recession. For this we calibrate a model that allows for different types of equilibria descriptive of both Spain and France, the latter used as a benchmark country. We complement this analysis with two counterfactual exercises that throw some more light on the Spanish labor market and the making of its housing bubble. As it will become evident in the next pages our paper will go beyond the theoretical framework and will rely, when possible, on the available data.

Recent developments and growth figures in Spain and France stand in stark contrast. ${ }^{1}$ While Spain is currently fighting its way out of a severe and long-lasting recession, apparently with positive results that indicate a clear change in the trend, France, on the other hand, is slowing down and even grinding to a halt. But this is just the tip of the iceberg. Prior to these new events, however, Spain had to undo (and still has to) much of its previous wrongdoings while aiming its guns on a different target. Indeed, austerity measures were joined by a clear consensus that the construction industry could no longer be the economy's main driver.

Our contribution in this paper offers a possible answer to what brought these two countries to their current state of economic affairs and the diverging paths undertaken in both cases. What we contend is that Spain, unlike France, has had to undergo (and still has) a deep structural change in its productive model - or a switch between different equilibria as it will become clear later. This took place basically out of the necessity to move away from the construction industry and into other more highly value-added activities. $^{2}$ The "brick sector", as has been dubbed in Spain, was hailed as the chicken of the golden eggs during most of the early 2000s. However, as credit became scarce and investors and construction companies began to pull out of the sector, the economy started on a downhill slide that was aggravated by the international crisis of 2007-08 and that made the unemployment rate hit new records - $26 \%$ in 2013 along with more than $50 \%$ youth unemployment.

On the onset of the current crisis both countries were positioned on the same spot in terms of unemployment. By 2006 both unemployment rates stood at virtually the same

\footnotetext{
${ }^{1}$ See Figure 1 and Table 1 below, as well as Figures 3 through 7 in the next section.

${ }^{2}$ Such preference has been called out from different quarters lately, see among many, the OECD Economic Surveys for Spain (2005, 2014), the OECD Report (2007) on competitiveness and the value chain, the IMF multi-authored Working Paper on competitiveness in the Southern Euro Area, and the McKinsey\&Company-Fedea Growth Agenda for Spain (2010).
} 
level, 8.5\% according to the OECD Economic Outlook (2014). But the similarities end right there. Higher GDP growth rates in Spain prior to the crisis were fueled by the housing bubble which was in turn sparked by the very low interest rate policy of the European Central Bank. Notice that this "artificial" growth brought the unemployment rate down from "normal" to unprecedented low levels, equaling that of France in 2006. We say unprecedented because the natural or equilibrium rate of unemployment in Spain has been estimated to be around $14-20 \%$ in the years preceding the bubble (see Estrada et al. 2000, or Mc Morrow and Roeger, 2000). We argue that the sudden increase of the unemployment rate during and after the crisis was mainly due to a substantial reallocation of resources. This was the natural consequence of putting all eggs in one basket. In other words, once the need for a change in the Spanish productive model became noticeable, it also became self-evident that the transition process towards another kind of economy was not going to be an easy walk.

The reason we focus so eagerly on the Spanish economy responds to what we think is a major structural change and, as a result, a change in the direction from previous years. France will only be used as a reference for comparison purposes, mainly to highlight the notable changes that took place recently in its next-door neighbor. It must be noted that France, unlike Spain, has not diverted as many resources to the construction industry during the pre-crisis years and, thus, has not experimented a swift change in its macroeconomic fundamentals.

Figure 1 shows a clear break in the Spanish macro data before and after the crisis in 2007.3 GDP growth took a deep plunge with the sudden halt of activity in the construction industry while the unemployment rate rose to record highs at levels not seen since the middle 1980s and 1990s. For its part, France remained very much stable in comparison with clear signs of stagnation in more recent years.

\section{Figure 1: Economic performance compared}

(a) GDP growth (\%)

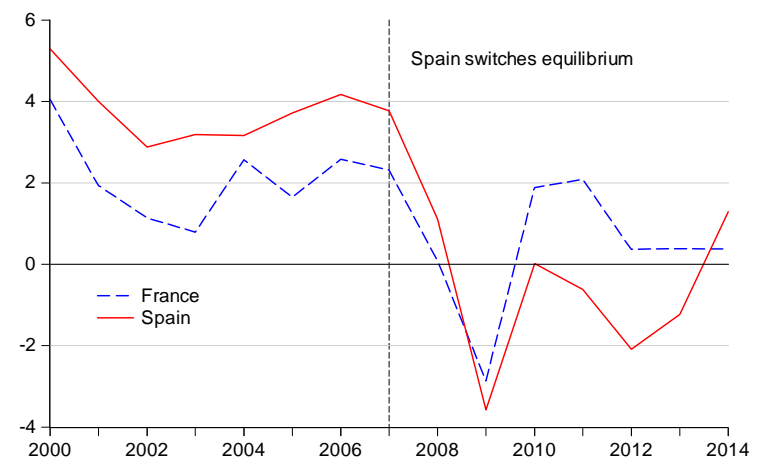

(b) Unemployment rate (\%)

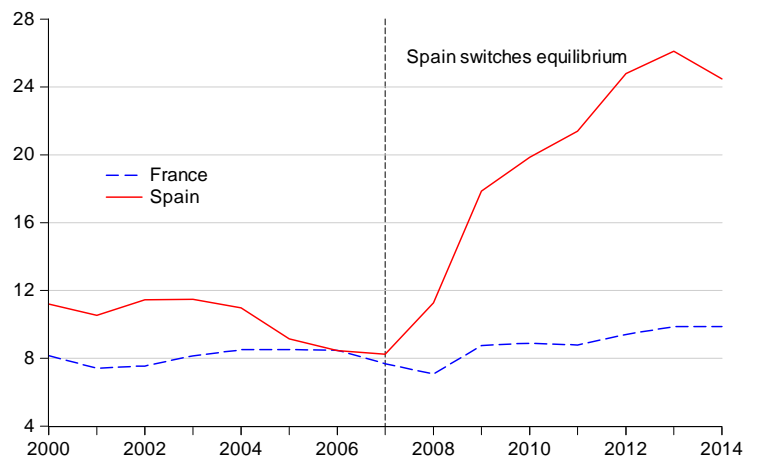

Source: Based on OECD Economic Outlook 96 (2014); 2014 data are projections.

\footnotetext{
${ }^{3}$ Appendix A exhibits all the data sources used in this study.
} 
Table 1 highlights the economic performance of both countries in recent years and also shows the OECD forecasts for the coming few years. According to the data it seems that, in both cases, recovery is well under way. We remain, however, a bit skeptical about the prospect and instead focus alone on the evident change of trend in the Spanish economy. The year 2014 has been labeled as an inflection point towards the right economic path, ${ }^{4}$ as GDP growth went from negative 1.2 to positive 1.3 and the unemployment rate dropped almost 2 p.p. from a still high $26 \% .^{5}$

Table 1: Economic performance, recent years

\begin{tabular}{lrrrrr}
\hline \hline & 2012 & 2013 & 2014 & 2015 & 2016 \\
\cline { 2 - 6 } (a) GDP growth (\%) & & & & & \\
France & 0.367 & 0.384 & 0.371 & 0.764 & 1.452 \\
Spain & -2.089 & -1.230 & 1.290 & 1.742 & 1.947 \\
\hline & & & & & \\
(b) Unemployment rate (\%) & & & & & \\
France & 9.39 & 9.85 & 9.86 & 10.15 & 10.05 \\
Spain & 24.78 & 26.09 & 24.47 & 23.05 & 21.93 \\
\hline
\end{tabular}

Source: OECD Economic Outlook 96 (2014); 2014, 2015, 2016 data are projections.

To come to grips with this reversion of the Spanish economy we make use of the equilibrium and welfare analysis as discussed in Albrecht and Vroman (2002) and Davidson et al. (2008). Albrecht and Vroman (2002) present a matching model with endogenous skill requirements where employers create both high and low-skill vacancies, and where it is also assumed that a low-skill job can be done by either type of worker yet high-skill jobs can only be filled by high-skill workers. The model suggests that low-skill workers are generally better off the greater the fraction of low-skill vacancies while the opposite is true for high-skill workers. Likewise, firms with low-skill requirements are generally better off the greater the fraction of low-skill job candidates.

Two equilibria are possible: cross-skill matching (CSM) and ex-post segmentation (EPS). The equilibrium is of the CSM type when high-skill workers and low-skill vacancies are matched, and EPS when these potential matches do not meet (e.g. high-skill workers only work in high-skill jobs). Changing the model's parameters can yield three scenarios: (i) a CSM-CSM change; (ii) a CSM-EPS switch; and (iii) an EPS-EPS change. As it will become clear later, only (ii) will be of relevance for us. We argue that this 'switch' between equilibria can be satisfactorily used to explain the structural

\footnotetext{
${ }^{4}$ See the Banco de España Annual Report (2013) for a comprehensive study on the change of course in the Spanish economy.

${ }^{5}$ Indeed, the projected OECD 2014 figures have been recently supported by the INE (Spanish Statistical Office) and stand at $1.4 \%$ for GDP growth and $24.45 \%$ for unemployment. French yearly figures for 2014 by the INSEE (French Statistical Office) were not available by the time of writing this paper.
} 
change taking place in Spain during the crisis years, especially as related to the housing bubble and the misallocation of resources that resulted from it.

\section{Feeding the monkey: The Spanish bubble}

Delving into the numbers of the Spanish construction and housing industries might get us closer to the truth about the recent structural change - or switch between equilibria to use a more technical term. A smaller economy than its bigger European partnerswith almost only half the population of Germany and three quarters the population of countries like Italy, France, or the UK - Spain boasted as many as double the workers in the construction sector as in Germany in 2007, right at the peak of the bubble. Table 2 shows the evolution of construction jobs in major European economies up to the critical 2007 year mark.

But what put Spain in this awkward position? What made for the profligacy in the construction industry, which is clearly reflected in the excessive number of jobs prior to the 2007 crunch? A more than possible yet usually overlooked hypothesis is that of the booms and busts cycles as laid out by the Austrian School, and recently discussed by Calvo (2013) in a non-technical paper that goes over the anatomy of crises. In setting interest rates too low for too long by way of a monetary expansion, central banks arguably pave the way for higher asset and real estate prices and, eventually, for overall inflation. ${ }^{6}$ Following with this reasoning, it is contended that extremely low real interest rates might divert resources into activities that would not have been targeted otherwise (e.g. housing). In other words, that due to the artificially low cost of credit resources can be badly allocated, turning the situation into an artificial boom - what Austrians label malinvestment.

Table 2: Construction jobs pre-crisis, Spain in context

\begin{tabular}{|c|c|c|c|c|c|c|}
\hline & 2002 & 2003 & 2004 & 2005 & 2006 & 2007 \\
\hline Spain & $2,189,274$ & $2,310,524$ & $2,455,722$ & $2,657,643$ & $2,797,500$ & $2,880,513$ \\
\hline Germany & $1,824,337$ & $1,697,818$ & $1,623,974$ & $1,515,465$ & $1,498,760$ & $1,521,752$ \\
\hline Italy & $1,574,979$ & $1,705,742$ & $1,748,373$ & $1,809,834$ & $1,844,895$ & $1,964,195$ \\
\hline France & $1,470,596$ & $1,494,723$ & $1,547,648$ & $1,538,128$ & $1,651,546$ & na \\
\hline United Kingdom & $1,307,459$ & $1,322,636$ & $1,347,409$ & $1,392,009$ & $1,393,461$ & na \\
\hline
\end{tabular}

Source: EUROSTAT and INE (2015).

\footnotetext{
${ }^{6}$ For early references on the Austrian School in relation to booms and busts cycles and monetary expansion see, most notably, Mises (1912) and Hayek (1931); for other more up-to-date references not necessarily in line with the Austrians see, for example, Bordo and Landon-Lane (2013) and the ones cited in Calvo (2013).
} 
Even when it is not our intention here to analyze this claim further, we think it provides with a clear and more than reasonable motivation for the structural break the Spanish economy is currently undergoing. Figure 2 illustrates this 'break' to some extent: mortgages and construction jobs experienced a remarkable growth during the pre-crisis period which was accompanied with negative real interest rates in most of the years. This process is now being reverted to some degree after the deflationary forces have set in and have brought interest rates to a higher level. This, however, is not devoid of serious consequences as spiralling increases in house prices have been combined with increases in home ownership during the bubble years (see Garriga, 2010) - which, in turn, plays against those facing mortgage obligations under the new higher interest rate scenario. Both the long-term interest on Spanish government bonds and the 12month Euribor display similar patterns, which were again driven down to very low levels during 2012-2014 (shown in Figure 3) due to further monetary expansion by the ECB in the face of these "deflationary threats". ${ }^{7,8}$

\section{Figure 2: Housing bubble in Spain}

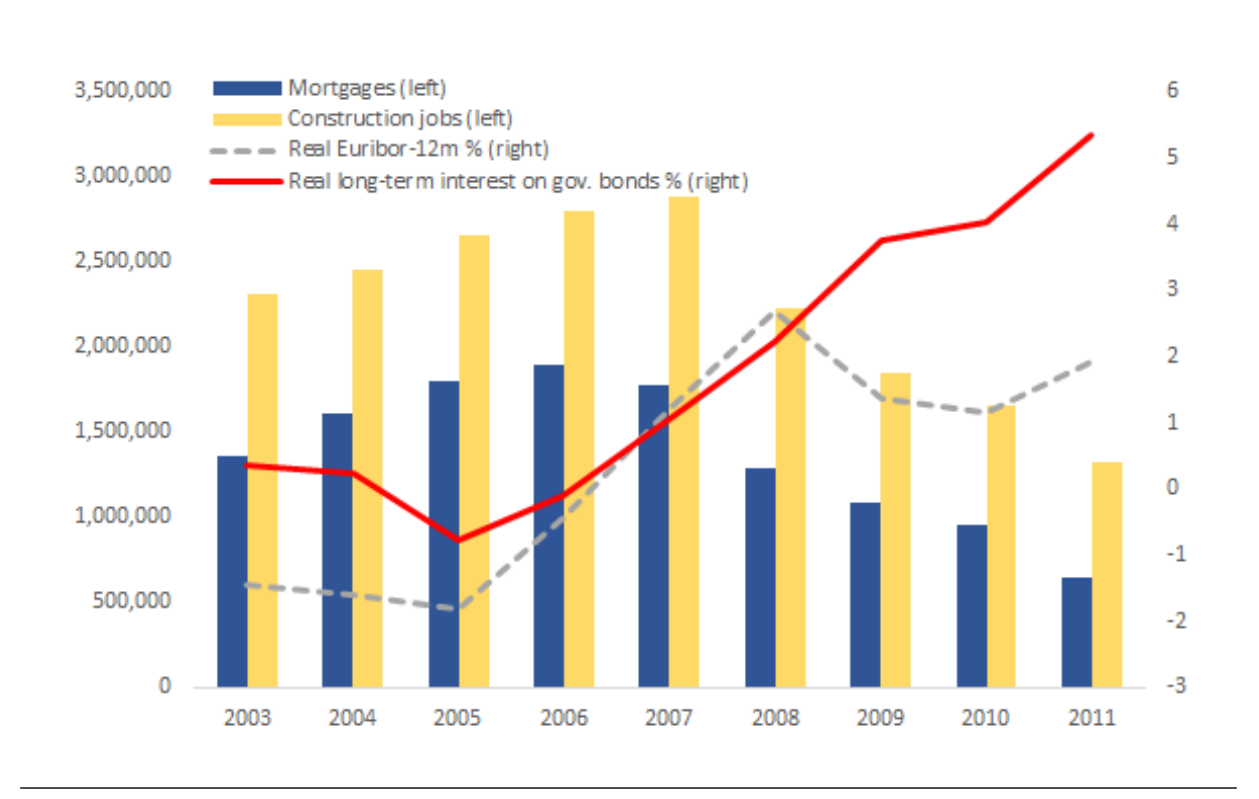

Sources: Based on OECD Economic Outlook 96 (2014), Spanish Ministry of Development and INE (2015), and Bank of Spain (2015).

Figure 3 clearly shows the sharp increase - from extremely low levels - of real interest rates in Spain after 2007 in comparison to those in France. Notice too the recent drop in both countries as a result of the loose European monetary policy. It is hardly questionable that these exceptionally low rates have not contributed, at least in part,

\footnotetext{
${ }^{7}$ Euribor-12m, for example, is the interest rate most commonly used to calculate mortgage payments in Spain, where mortgages are usually of the variable rate type and are calculated as Euribor $+\mathrm{X} \%$ with $\mathrm{X}$ anything between $0.75 \%$ and $2 \%$.

${ }^{8}$ Correlation between the interest rates, on the one hand, and construction jobs or mortgages on the other, is strongly negative as clearly inferred from the figure.
} 
to give shape to the housing bubble in Spain. We cannot assess the magnitude of this phenomenon here, and it is not our goal; rather, we propose a fairly simple setting to rationalize the structural change in the Spanish economy in terms of a switch between equilibria.

\section{Figure 3: Real interest rates compared}

(a) Long-term government bonds (\%)

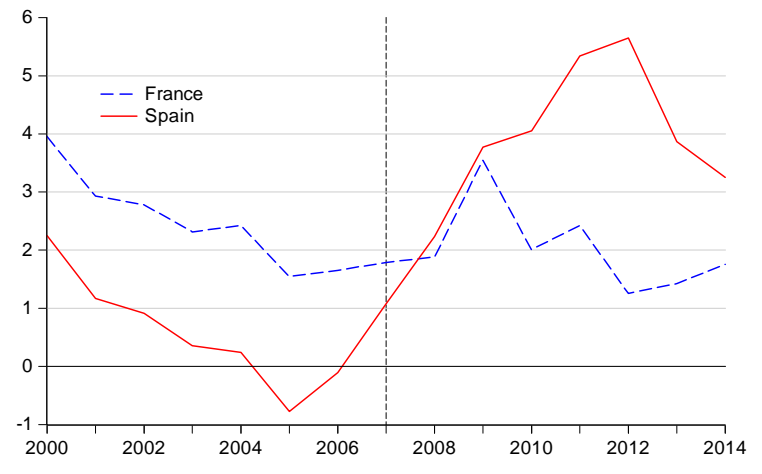

(b) Euribor-12m (\%)

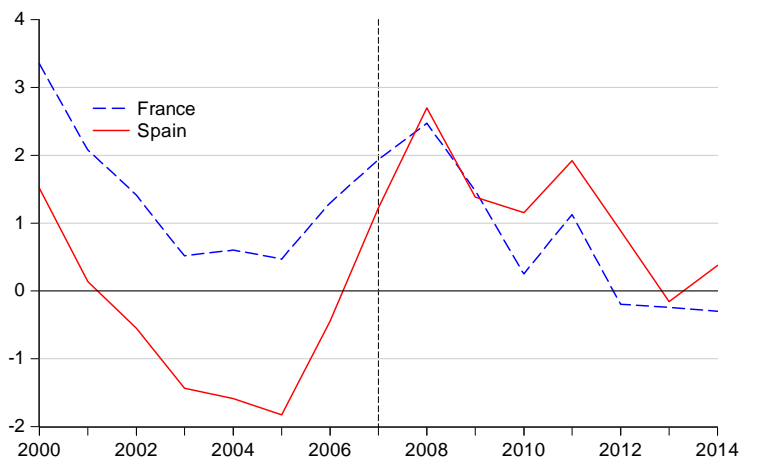

Source: Based on OECD Economic Outlook 96 (2014) and Bank of Spain (2015).

A second point worth stressing is the meager productivity growth registered in Spain prior to 2007. Figures $4 \mathrm{a}$ and $4 \mathrm{~b}$ show the different patterns for both Spain and France for the pre and post-crisis years. As widely known in the literature, Spain features what has been commonly referred to as a two-tier labor market (see Bentolila et al., 2012a and 2012b, for recent references). Such markets are usually characterized by strong insider-outsider mechanisms where 'insiders' can command relatively higher wages and virtually lifetime employment at the expense of their fellow 'outsiders' workers, who remain poorly paid and with limited productivity gains due to the temporary character of their contracts (see Lindbeck and Snower, 1988, in general, and Bentolila et al., 2012b, for the Spanish case).

Spanish productivity growth was remarkably low during 2000-2007 as seen in Figure 4a while it looked much healthier once economic restructuring and the stripping down of the construction industry began in later years. Figure 4 b shows a clear recovery in this category despite the signs of slowing down after 2012, in coincidence with further monetary expansion and lower real interest rates. How else should we interpret the economic growth prior to 2007 in Spain (Figure 1a) but as a result of a misdirection of resources as revealed by low productivity growth (Figure 4a) and the resulting housing bubble? 
(a) Growth rate, pre-crisis (\%)

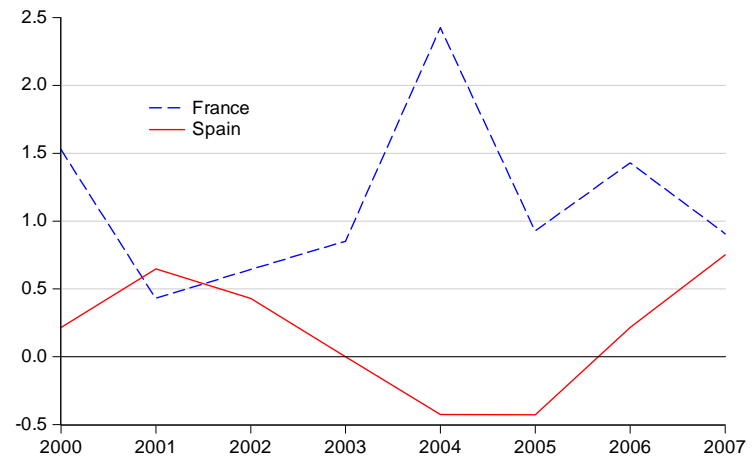

(b) Growth rate, post-crisis (\%)

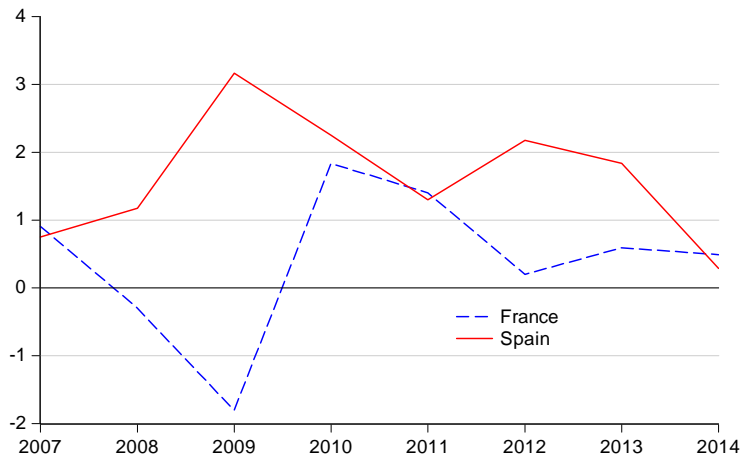

Source: Based on OECD Economic Outlook 96 (2014).

Another unambiguous indication of the Spanish economy being out-of-step before 2007 is given by the evolution of the unit labor costs - which can be defined as the average cost of labor per unit of output. Figure 5a presupposes a real disconnect between workers' compensations and labor productivity for too many years during 'bubble times'. Figure 5b instead reverses the previous trend as productivity growth is now catching up with previous wage hikes.

\section{Figure 5: Unit labor costs compared}

(a) Growth rate, pre-crisis (\%)

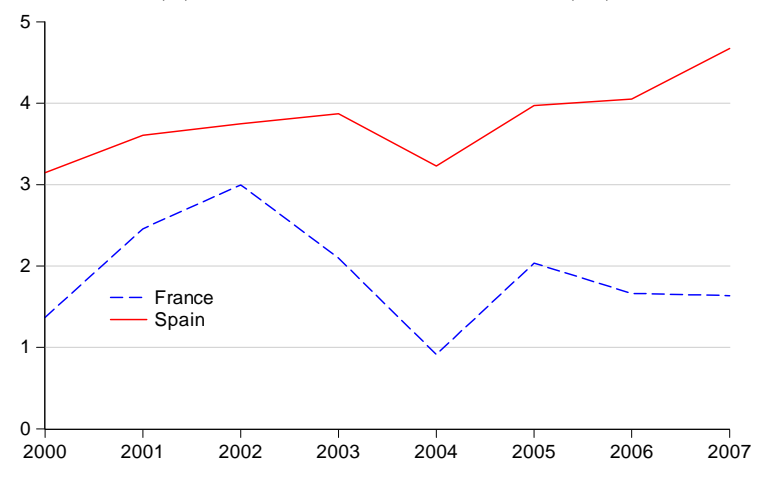

(b) Growth rate, post-crisis (\%)

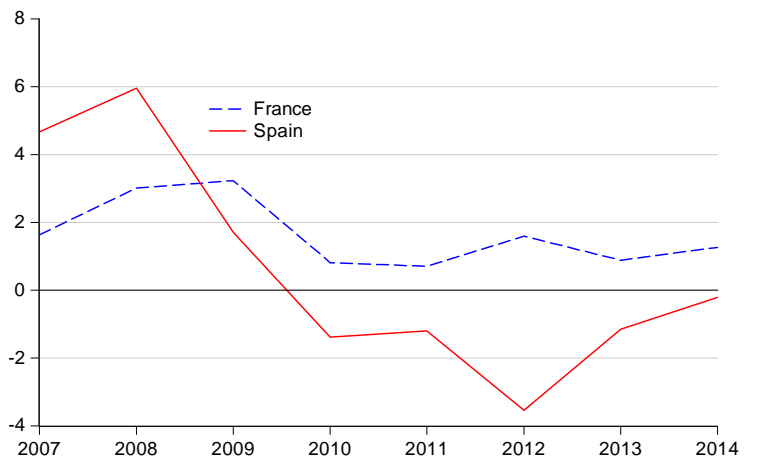

Source: Based on OECD Economic Outlook 96 (2014).

Figure 6 throws more light on the major distortion within the Spanish economy. The output gap, defined as the deviation of actual GDP from potential GDP, as a percentage of potential GDP, was significantly high in Spain prior to the crisis. The potential gross domestic product is defined by the OECD's Economic Outlook as the level of output that an economy can produce at a constant inflation rate. Producing more than the potential level of output, as was the case of Spain before the crisis, comes at the cost of rising inflation, as was also the case there. ${ }^{9}$ The numbers were reversed to

\footnotetext{
${ }^{9}$ China, too, has recently shown clear signs of overheating, with a housing overstock running up in the millions, a GDP growth that hasn't fallen below $7 \%$ in the last two decades, and rising commodity prices (especially of food).
} 
negative levels in recent years and respond to the adjustment or structural change the economy is now being undergoing; that is, partly to the deflationary forces now being at work.

\section{Figure 6: Output gaps compared}

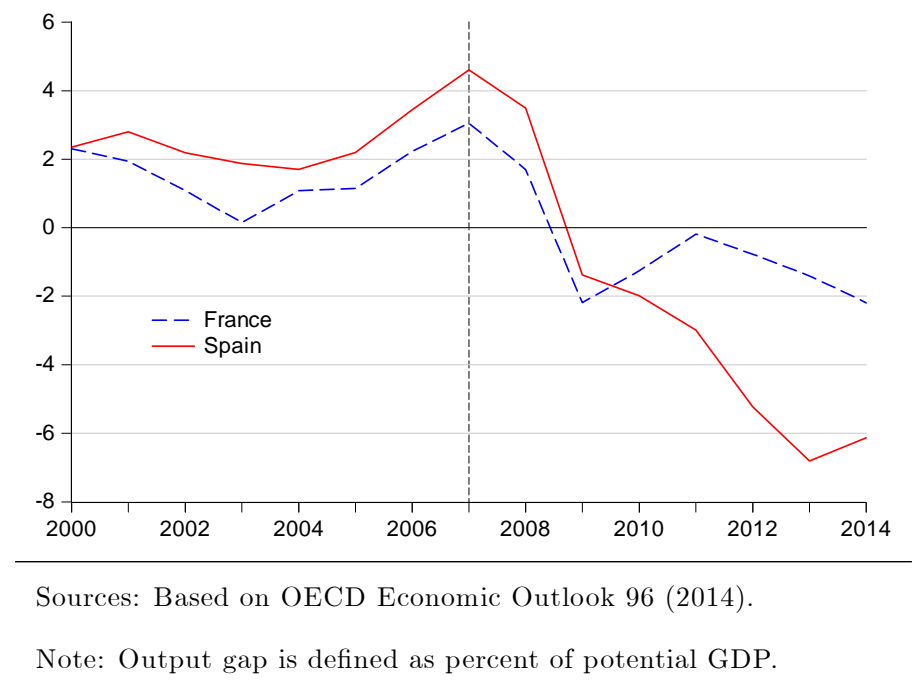

A final word must be said on employment before concluding this section. As explained earlier, Spain experienced several years of significant growth prior to the crisis along with low productivity rates (Figures 1a and 4a). During that same period total employment in Spain rose by about 5 million workers - or, what is the same, an unheard average annual rate of more than 4\% for 2000-2007 (Figure 7a). With the burst of the bubble in 2007 more than 3 million jobs were destroyed at an approximate average rate of $2.4 \%$ in 2008-2014, reverting the previous positive trend. Self-employment-a traditional component of the construction industry - showed a similar pattern (Figure 7b), first by going up by roughly 200,000 jobs and then by falling for a longer distance.

Figure 7: Employment trends compared

(a) Total employed, workers

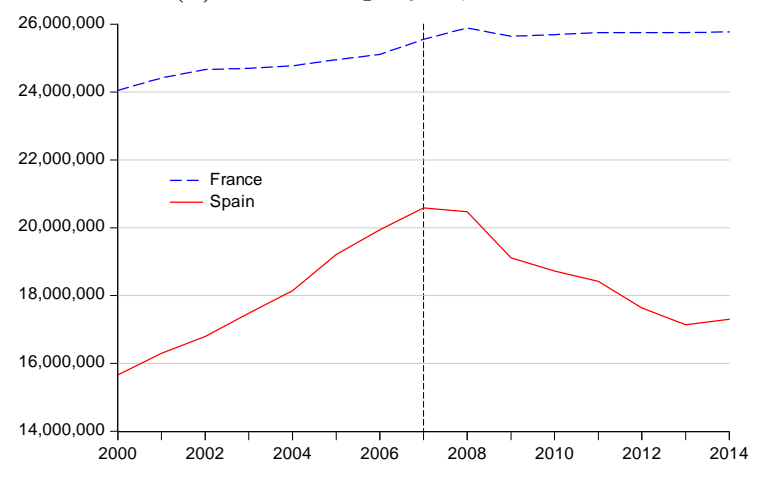

(b) Total self-employed, workers

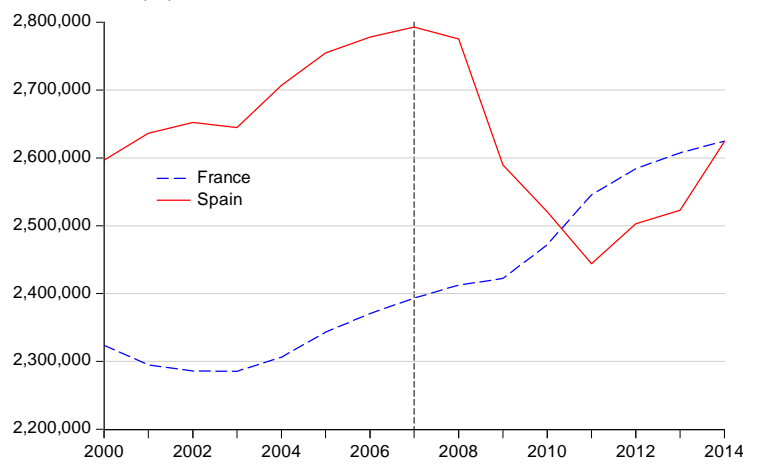

Source: Based on OECD Economic Outlook 96 (2014). 
The structural change taking place in Spain in recent years can be seen as the natural correction of several years of diverting resources into highly unproductive activities. Such unproductive activities (e.g. the housing boom) have been encouraged, we believe, by a combination of EU and Spanish local policies, to wit: first, a very loose monetary policy that, for many years, has been feeding the monkey of 'malinvestment' by making credit extremely cheap and easy to get; and second, a set of stringent labor market policies that have affected the already immobile Spanish labor force.

\section{Model}

We briefly sum up the model in Albrecht and Vroman (2002) we use for our analysis. It is an infinite horizon model with many risk-neutral workers with discount rate $r$ who differ in their skills - an exogenous fraction $q$ is low-skill, $L$, and $1-q$ are high-skill, $H$. Firms are of measure one, they place vacancies at the exogenous cost $c$ and decide endogenously whether to operate with low or high-skill technology. Thus a fraction $\phi$ of vacancies is low-skill and a fraction $1-\phi$ is high-skill. A high-skill worker is allowed to take both types of jobs whereas a low-skill worker can only fill a vacancy that corresponds to his type. Wages are determined in the Nash bargaining process assigning the wage $w_{L}\left(w_{H}\right)$ to a worker of type $L(H)$ working in a job of type $L(H)$, and $w_{L(H)}$ to a worker of type $H$ working in a job of type $L$ with $w_{H}>w_{L(H)}>w_{L}$. If a worker is unemployed he is entitled to the unemployment benefit $b$ and any worker can refuse the job if his reservation wage is not met. Moreover, jobs are lost at an exogenous rate $\delta$.

In the described setup two types of equilibria may be realized: the equilibrium with cross-skill matching (CSM) and the equilibrium with ex-post segmentation (EPS). CSM occurs when high-skill workers and low-skill vacancies match, and EPS takes place when these potential matches do not meet, i.e. high-skill workers only work in high-skill jobs. The type of equilibria achieved depends on the expectations of high-skill workers about the labor market and their willingness to accept a low-skill job.

Firms and workers meet according to a matching technology $M(u, v)=2 \sqrt{u v}$ where $u$ represents unemployed workers (unemployment rate) and $v$ vacancies. In this process an endogenously determined fraction $\gamma$ of unemployed workers will be low-skill. Furthermore, arrival of jobs to workers happens at a rate $\frac{M(u, v)}{u}$, arrival of workers to employers at a rate $\frac{M(u, v)}{v}$, and market tightness is defined as $\theta=\frac{v}{u}$. We can write the job arrival rate to workers as $m(\theta)=2 \sqrt{\theta}$ and workers' arrival rate to firms as $z(\theta)=\frac{2}{\sqrt{\theta}}$. If the match succeeds, the worker gets a wage $w_{i}, i=L, L(H), H$, with an expected lifetime utility $W_{i}$ from earning the wage $w_{i}$. Any type of worker employed in a low-skill firm produces $y_{L}$, and a high-skill worker's production in a high technology 
firm produces $y_{H}$. Notice that high-skill firms are more productive than low-skill firms, $y_{H}>y_{L}$, and that the firms' profits depend on the level of output and the incurred costs, namely, wages and searching. Profits are defined as $y_{L}-w_{L}-c$ and $y_{L}-w_{L(H)}-c$ in the case that a low-skill firm employs a low and high-skill worker, respectively, and $y_{H}-w_{H}-c$ in the case that a high-skill firm employs a high-skill worker. We also have that a firm's expected discounted profits are $J_{i}, i=L, L(H), H$. Figure 8 sketches the matches, wages, and output obtained under the two equilibria.

Figure 8: Possible matches between workers and firms

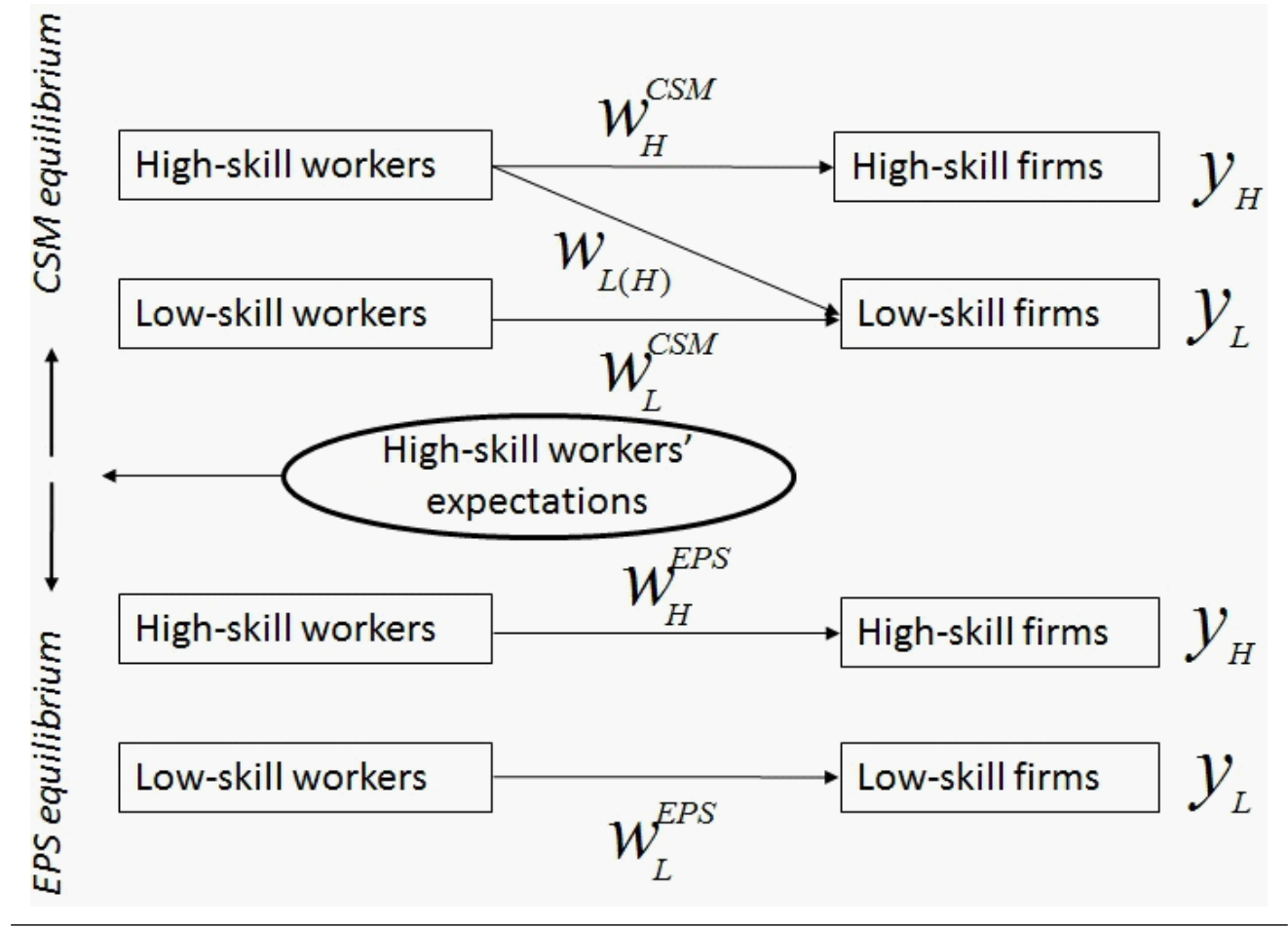

If the agreement between a worker and a firm is not achieved, the worker's income corresponds to the unemployment benefit $b$ and his lifetime expected utility is $U_{j}, j=L$, $H$. In such a case, the firm ends up with an unfilled vacancy of value $V_{j}, j=L, H$. We thus have that $W_{i}$ stands for the value of working and $U_{j}$ for the value of unemployment, while $J_{i}$ stands for the value of the job and $V_{j}$ for the value of the vacancy for the corresponding type. There is something to bargain over if the worker obtains a positive surplus when working $W_{H}-U_{H}>0, W_{L(H)}-U_{H}>0$ and $W_{L}-U_{L}>0$, and when the firm gets positive surplus by hiring the worker, i.e. $J_{H}-V_{H}>0, J_{L(H)}-$ $V_{L}>0$ and $J_{L}-V_{L}>0$. Wages are then chosen to maximize the weighted worker's and firm's surpluses, $\left(W_{H}-U_{H}\right)^{\beta}\left(J_{H}-V_{H}\right)^{1-\beta},\left(W_{L(H)}-U_{H}\right)^{\beta}\left(J_{L(H)}-V_{L}\right)^{1-\beta}$ and $\left(W_{L}-U_{L}\right)^{\beta}\left(J_{L}-V_{L}\right)^{1-\beta}$, respectively, where $\beta$ represents the worker's bargaining power. Firms enter the market as long as the value of opening a vacancy is non-negative. Once many firms enter the market the value of the vacancy hits zero and the process stopsthus $V_{L}=0$ and $V_{H}=0$ hold in all periods. 
Workers may experience spells of employment and unemployment. When the flow of workers into and out of each employment state coincide the steady-state equilibrium is achieved. Previously employed workers of each type who lose their jobs coincide with the number of unemployed workers that find the job

$$
\begin{aligned}
\delta E_{L} & =\phi m(\theta)\left(q-E_{L}\right), \\
\delta E_{H} & =m(\theta)\left(1-q-E_{H}\right)
\end{aligned}
$$

where $E_{L}$ denotes employed low-skill workers $E_{L}=q-\gamma u$, and $E_{H}$ denotes employed high-skill workers $E_{H}=1-q-(1-\gamma) u$. Like Albrech and Vroman (2002) we concentrate on the steady state equilibrium results. More details on the equilibrium equations can be found in Appendix B.

\section{Results}

To make sense of the model above and better understand the housing bubble and structural change that has recently taken place in Spain we propose three different exercises. First, we calibrate the model with real data for France and Spain as these two countries' performances, especially in terms of unemployment, stand in stark contrast during the recent crisis period. We suggest various possibilities concerning the parameters and equilibria as to make sense of the countries' diverging unemployment rates. ${ }^{10}$ Second, we carry out a first counterfactual experiment focusing on the unemployment rate in Spain and highlighting the effects of the mild flexibilization reform undertaken in recent years. And third, we propose a second counterfactual experiment with an eye on the interest rate and the making of the Spanish bubble.

One hard piece of evidence worth noting is that both unemployment rates went from $8.5 \%$ in 2006 to very different plateaus in 2013 at the peak of the recession $-9.9 \%$ in France and $26.1 \%$ in Spain. This is quite a leap indeed for Spain and deserves some thought. We can summarize our analysis below by arguing, first, that a change in the productivity differential in the calibrated model can lead to a change of equilibria in Spain as to render the economy quite out of balance (e.g. the burst of bubble and the ensuing skyrocketing unemployment); second, that the existing labor market institutions in Spain are not suitable to deal with the unemployment problem and, moreover, that in the Spanish experience they might have proved highly detrimental as the economy switched between equilibria; and third, that the housing bubble was, in all probability, behind the structural change in Spain.

\footnotetext{
${ }^{10}$ Bentolila et al. (2012a) develop a parallel analysis for France and Spain with quarterly data yet with a focus on the transition between equilibria.
} 


\subsection{Calibration}

We adapt and calibrate Albrecht and Vroman (2002) to fit France's and Spain's experiences in 2000-2013. We use the following baseline parameters: the bargaining power of workers is the same as that of the firms, $\beta=0.5$; the productivity of low-skill workers is $y_{L}=1$ whereas that of high-skill is, depending on the case, either $y_{H}=1.05$ or $y_{H}=1.2$ - that is, we let both economies start from different gaps, one rather trivial and the other not so; moreover, the two countries differ in parameters that characterize the skill composition of workers and the labor market characteristics - the low-skill share of workers is set to the average value of $q$ in 2000 and 2011 (the only two periods available) as $q^{E S P}=0.54$ and $q^{F R A}=0.33$; the jobs last on average 10 years in Spain and 11.7 in France, thus $\delta^{E S P}=0.1$ and $\delta^{F R A}=0.085$; unemployment benefits represent about $60 \%$ of previous wages in both countries - having in mind this value we set $b$ to represent about $60 \%$ of average wages $;{ }^{11}$ agents discount the future at rates $r^{E S P}=0.35 \%$ and $r^{F R A}=1.2 \%$, as these correspond to the averages in $2000-2013 ;^{12}$ and finally, the vacancy cost is set to generate the target level of unemployment as to mirror the values found in the data between 2000-2013.

In order to rationalize the bubble episode in Spain and the resulting structural change, we will allow for a widening of the productivity gap once we have our baseline calibrations done. These baseline calibrations involve two particular cases, namely: the small (5\%) and big (20\%) productivity gap cases discussed below. Our goal is to see how the model behaves in terms of how close we are to the unemployment rates in Spain and France as derived from the real data. These two extreme cases are useful to see the effects in both economies with a certain margin of discretion, with special focus on the Spanish bubble, since bubbles are not unambiguously accounted for in the literature. Ventura (2002), for instance, claims that "bubbles tend to appear and expand in countries where productivity is low relative to the rest of the world", something which is not far from the story presented above for Spain (see, especially, Figure 4a). Other, like Miao and Wang (2012), purport that the collapse of bubbles leads to a recession and a fall in productivity levels - this, in part, was true for Spain yet productivity showed strong signs of recovery (see Figure $4 \mathrm{~b}$ above).

\footnotetext{
${ }^{11}$ We define average wage under both types of equilibria as follows

$$
\begin{aligned}
\bar{w}^{C S M} & =\frac{E_{L}}{E_{L}+E_{H}} w_{L}+\frac{E_{H}}{E_{L}+E_{H}} \phi w_{L(H)}+\frac{E_{H}}{E_{L}+E_{H}}(1-\phi) w_{H}, \\
\bar{w}^{E P S} & =\frac{E_{L}}{E_{L}+E_{H}} \phi w_{L}+\frac{E_{H}}{E_{L}+E_{H}} w_{H} .
\end{aligned}
$$

${ }^{12}$ As discount rate we take the average for Euribor-12 since this is, we believe, closely related to the housing bubble in Spain.
} 


\subsubsection{Spain vs. France: Case 1 (small gap)}

We first analyze the case where the gap between low and high-skill workers' productivities is relatively small - for this we take a 5\% gap. The values given to the parameters in both economies are shown in Table 3 below. Moreover, the level of unemployment benefits is set to be roughly $60 \%$ of average wages.

Table 3: Small productivity gap, baseline parameters

\begin{tabular}{lcccccccc}
\hline \hline & $y_{L}$ & $y_{H}$ & $b$ & $c$ & $r$ & $q$ & $\beta$ & $\delta$ \\
\cline { 2 - 9 } & & & & & & & & \\
Spain & 1 & 1.05 & 0.30 & 0.50 & 0.0035 & 0.54 & 0.5 & 0.100 \\
France & 1 & 1.05 & 0.35 & 0.45 & 0.0118 & 0.33 & 0.5 & 0.085 \\
\hline
\end{tabular}

For this set of parameters both economies start with a CSM equilibrium and with approximately the same rate of unemployment, $8.5 \%$, just to simulate the situation in 2006. However, as soon as we allow for a wider productivity gap things turn out differently: whereas France immediately switches to an EPS equilibrium Spain stays with the CSM for a bit longer. Under these conditions, when the productivity of low-skill workers is allowed to go down, the rate of unemployment increases in both countries and, besides, when Spain gets into the EPS equilibrium it is at a consistently high unemployment rate. In other words, when Spain switches between equilibria there seems to be a "jump" of the unemployment rate (e.g. structural change). We plot the steady state relationship between $y_{L}$ and $u$ for both countries in Figure 9 .

We can also observe that the unemployment rate is less sensitive to changes in $y_{L}$ in France or, what is the same, that there was no structural change there. The end of the lines to the right represent the collapse of the labor market in both countries, which happens when $y_{L}$ is very low and $u$ very high, and when $\phi \rightarrow 0$, which happens when no more low-skill jobs are offered as the productivity of low-skill workers is too low to entice firms into hiring them. This would take place at the same productivity differential in both countries (approximately 19\%) yet at a higher hypothetical unemployment rate in Spain. Finally, in order to generate the peak in the unemployment rate of Spain, or $u^{E S P} \approx 0.26$, the reduction in the productivity of low-skill workers should be of about $15 \%$. Notice that while the transition between equilibria is smooth in France it is more like a "jump" for Spain. Moreover, France will be perhaps less prone to a CSM as there is only one possible value for this to happen and many for the EPS, among which there is also the possibility that both equilibria coexist (at a $5 \%$ gap). In addition to this, and as commented at the start of this paragraph, France does not seem to need a jump or structural change, according to our calibrations, to move into the more efficient EPS result. Hence, assuming that France is, and has for long been, in an EPS is not far from reality. 


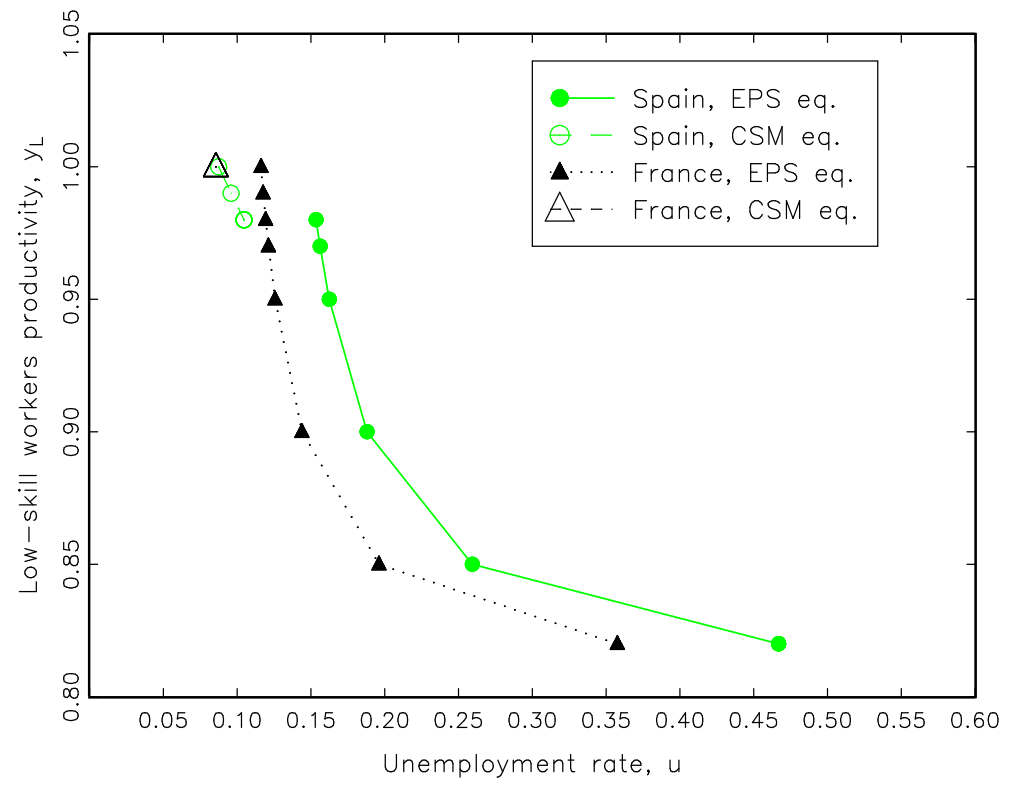

\subsubsection{Spain vs. France: Case 2 (big gap)}

Our second case depicts the more realistic event of a wider productivity differential between low and high-skill workers. We here set $y_{H}=1.2$ and $y_{L}=1$, a $20 \%$ productivity gap. Notice that the parameters used for this calibration shown in Table 4 below slightly differ from those above, mainly due to the fact that we want to guarantee that benefits are roughly $60 \%$ of average wages in both countries.

Table 4: Big productivity gap, baseline parameters

\begin{tabular}{lcccccccc}
\hline \hline & $y_{L}$ & $y_{H}$ & $b$ & $c$ & $r$ & $q$ & $\beta$ & $\delta$ \\
\cline { 2 - 8 } & & & & & & & & \\
Spain & 1 & 1.20 & 0.32 & 0.50 & 0.0035 & 0.54 & 0.5 & 0.100 \\
France & 1 & 1.20 & 0.40 & 0.40 & 0.0118 & 0.33 & 0.5 & 0.085 \\
\hline
\end{tabular}

For this set of parameters both France and Spain start in an EPS equilibriumthe CSM equilibrium does not exist. Allowing for a $20 \%$ gap now suggests that, in order to achieve the peaks in the unemployment rates in recent years, $u^{E S P} \approx 0.26$ and $u^{F R A} \approx 0.10$, the drop in productivity should be of about $13 \%$ in Spain and almost negligible in France. Figure 10 plots the new sets of equilibrium combinations between $y_{L}$ and $u$. This is consistent with findings in Bentolila et al. (2012a) that the impact of the recession in Spain was more deeply felt. Again, the end of the lines to the right (low $y_{L}$, high $u$ ) represent the collapse of the labor market as low-skill vacancies approach zero. Notice that the Spanish labor market would collapse "earlier" and at a much higher unemployment rate due to a smaller fraction of high-skill workers. 


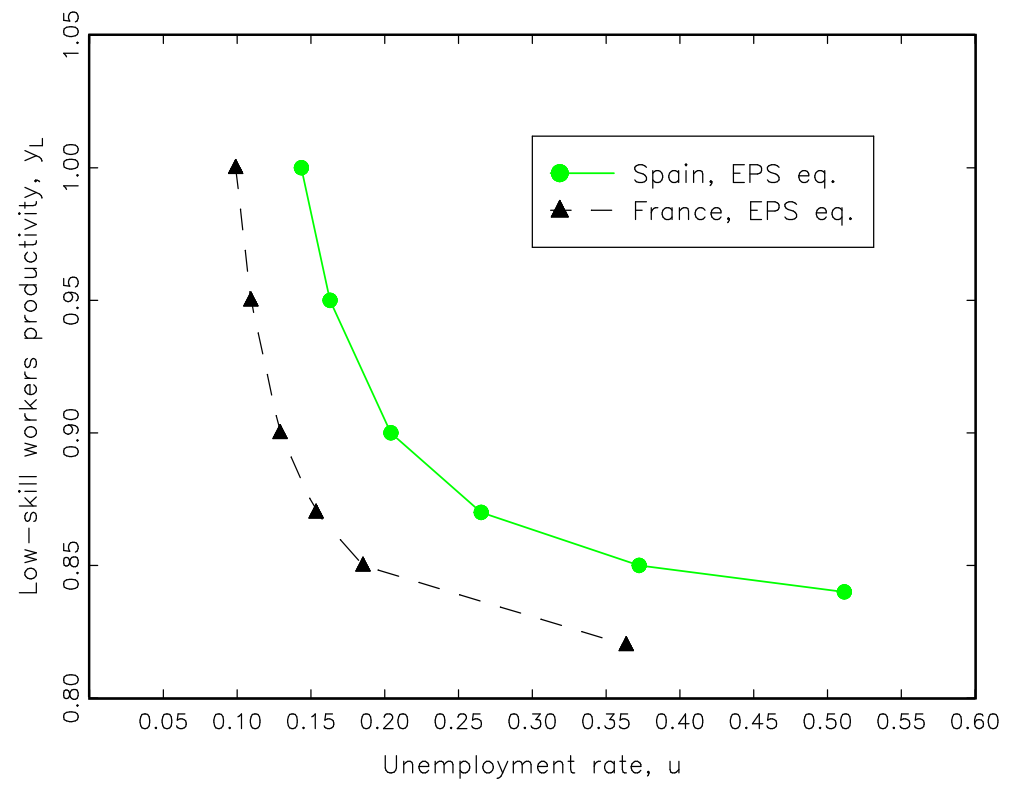

\subsection{Counterfactuals I: The Spanish labor market}

We now proceed with our first set of counterfactuals, as we believe it will further our understanding about the performance of the Spanish labor market after the recent flexibilization reforms. Our strategy goes as follows: we first derive an estimable equation for unemployment from our model above; then we estimate the equation using the available data; and last, we use the estimated model to obtain the contribution of the flexibilization variable to the change of the unemployment rate during the recent years. This contribution is computed through a dynamic simulation of the estimated model as follows: we first fix the exogenous variable at the level of certain arbitrary year, then we solve the model, and finally we retrieve the new path of the unemployment rate. For us, the simulation's initial year roughly corresponds with the beginning of the global crisis in Europe - we take 2007 as this year coincides with the lowest of unemployment in our period of analysis.

It can be demonstrated that the unemployment rate is given by the following general $\operatorname{expression}^{13}$

$$
u=f\left(\delta, q, c, b, r, \beta, y_{L}, \gamma\right)
$$

where unemployment is dependent on $\delta$, the rate at which jobs are lost, $q$, the share of low-skill workers, $c$, vacancy costs (more broadly interpreted here as 'market flexibility'), $b$, the unemployment benefit, $r$, the rate at which agents discount the future, $\beta$ the bargaining power of workers, $y_{L}$, the productivity of low-skill workers,

\footnotetext{
${ }^{13}$ The unemployment rate as derived from the model above is non-linear and quite burdensome for estimation purposes. The formal derivation is available on request but we will stick to the linearized version as this does not pose a serious drawback for our analysis.
} 
and $\gamma$, the fraction of low-skill unemployment.

Table 5 shows the results of the estimation for a dynamic, linearized, and much abridged version of the unemployment equation above. We can see that the estimated equation does not display all the variables alluded to in the definition because of missing data. We will focus on $c$ as this coefficient is somewhat descriptive of the labor market situation. For this we use an index on the strictness of employment protection (OECD) - notice that such coefficient is highly significant (5\%).

Further note that the interest rate is found to be significant, possibly due to the relatively high degree of credit dependency and the overly inflated construction and housing industries, as stated before. Moreover, the productivity coefficient $p y$ - defined here as labor productivity — can be ambiguous since the relationship between $u$ and $p y$ can be driven by other factors. Consequently, we should be careful with the interpretation of our results as these can be affected by endogeneity. ${ }^{14}$ A dummy variable $d^{07}$ for the crisis years is also entertained ( $=1$ in $2007-2013$ and $=0$ otherwise). We will now take a brief look at the simulation results.

\section{Table 5: Unemployment equation, OLS}

\begin{tabular}{|c|c|c|}
\hline \multicolumn{3}{|c|}{$\begin{array}{l}\text { Dependent variable: } u_{t} \\
\text { Spain, 1991-2013: }\end{array}$} \\
\hline & \multicolumn{2}{|c|}{ coefficient } \\
\hline cnt. & -6.76 & {$[0.002]$} \\
\hline$u_{t-1}$ & 0.40 & {$[0.025]$} \\
\hline $\ln c_{t}$ & 0.07 & {$[0.035]$} \\
\hline $\ln p y_{t}$ & 0.62 & {$[0.003]$} \\
\hline$d_{t}^{07}$ & 0.02 & {$[0.034]$} \\
\hline$r_{t}$ & 0.53 & {$[0.042]$} \\
\hline $\bar{r}^{2}$ & & 0.952 \\
\hline s.e. & & 0.011 \\
\hline$n$ & & 23 \\
\hline
\end{tabular}

Note: p-values in brackets.

Figure 11 shows how our single-equation estimation tracks the changes of the unemployment rate during 1991-2013. The gray shaded zone zooms in the recent recession years and goes from 2007, the lowest for the whole period, up to 2013. We now use the estimated model to calculate the contribution of the flexibilization variable $c$ to the change of the unemployment rate in 2007 through 2013.

\footnotetext{
${ }^{14}$ Introducing $p y$ in the unemployment equation answers the necessity of accounting for $y_{L}$, yet the former is a measure of aggregate productivity and the other the productivity of low-skill workers alone.
} 


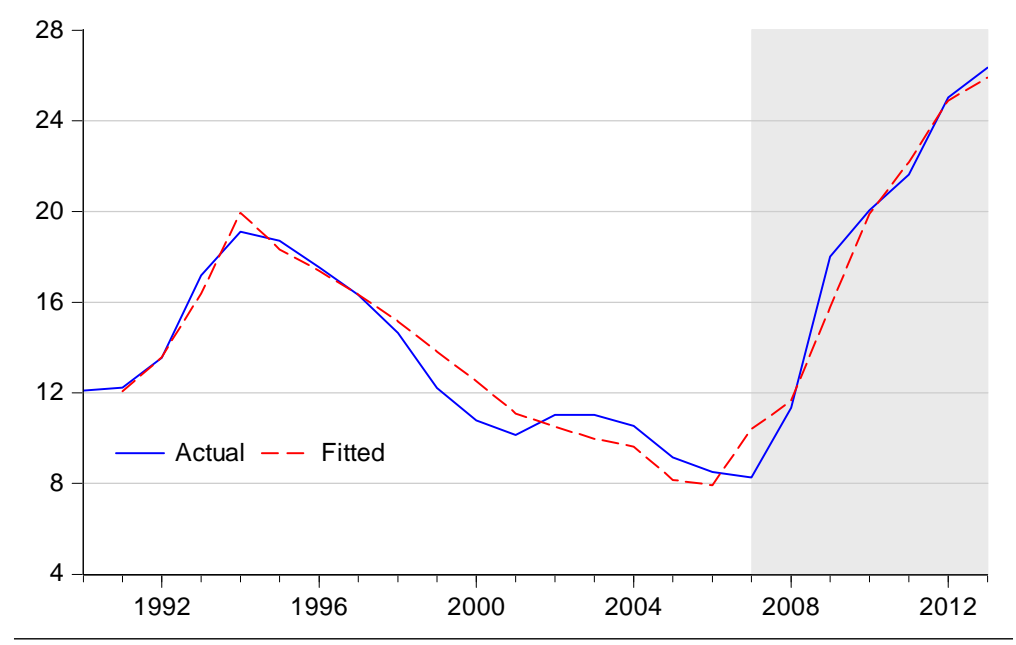

We fix $c$ to the simulation's starting year, 2007, and solve the model accordingly. Once we do this we are able to recover the new (simulated) path of the unemployment rate. Figure 12 is very revealing on the 'what ifs' regarding the policy measures related to $c$ and labor market performance in general. Figure 12 (a) shows the path of the unemployment rate had the employment protection indicator remained at the level of 2007 (in red), along with the actual trajectory (in blue). As shown there, flexibilization has contributed to a reduction of the unemployment rate of approximately 1.1 p.p.. Unlike a comparative statics exercise our simulation here takes account of the dynamics occurring within the subsample 2007-2013, and therefore the final effect on $u$ is the result of this summation of effects - even when this is only seen from 2010 onwards, when the first steps were taken in the direction of labor flexibilization. Figure 12 (b) exhibits both the evolution of this variable as well as its simulated path fixed at 2007 . According to our analysis here the Spanish flexibilization reform has thus fallen short of achieving a real improvement of the current conditions.

\section{Figure 12: Labor flexibility and unemployment in Spain}

(a) Unemployment rate $(\%)$

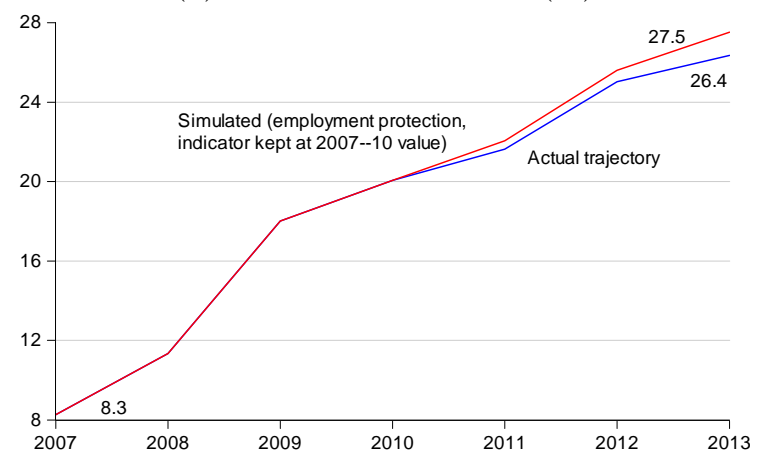

(b) Strictness indicator $(0=$ flexible to $6=$ tight $)$

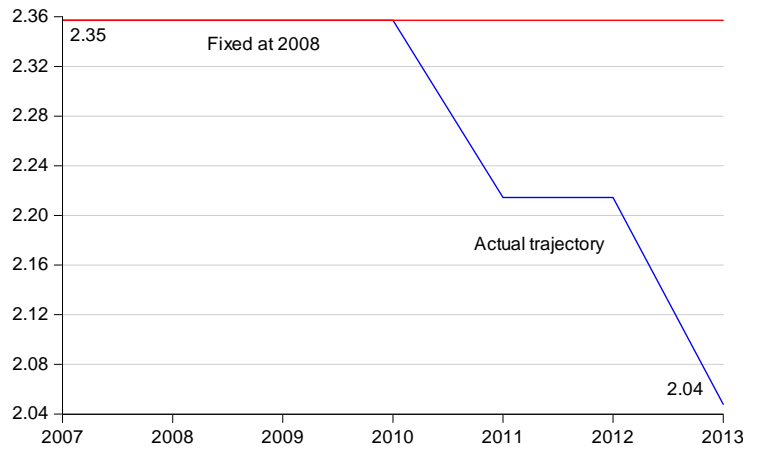




\subsection{Counterfactuals II: The Spanish bubble}

We undertake a separate yet similar counterfactual exercise in this section to throw some light on the role played by interest rates in the building-up of the Spanish bubble during the early years of the current century. As before, we follow the same methodological procedure regarding estimation and simulations, with the exception that we now have no theoretical derivation of the estimable equation. Moreover, our database at this point is rather limited and we should remain on the conservative side when reading through our simulations.

Table 6 shows two similar regressions, with the share of construction jobs on total employment being regressed upon the real interest rate and the output gap. Panel (a) on the left has the euribor-12 as a regressor whereas panel (b) on the right has the rate on government bonds. Both coefficients are highly significant and negatively signed, something which is clearly consistent with the story related earlier - that is, very low interest rates are a major driver behind the malinvestment and redirection of resources into the inflated construction industry.

In addition to the interest rate, the output gap is included as a regressor to highlight the overheating of the Spanish economy. Significant and positive coefficients in both equations are suggestive of a positive correlation between 'going beyond the means' and the housing bubble. In other words, this variable accounts for factors leading to the housing bubble and the increase of construction employment other than those brought about by very low interest rates.

Table 6: Construction jobs share equation, OLS

\begin{tabular}{|c|c|c|c|c|c|}
\hline \multicolumn{3}{|c|}{$\begin{array}{l}\text { Dependent variable: } s_{t} \\
\text { (a) Spain, 2002-2011: }\end{array}$} & \multicolumn{3}{|c|}{ (b) Spain, 2002-2011: } \\
\hline \multicolumn{3}{|c|}{ coefficient } & \multicolumn{3}{|c|}{ coefficient } \\
\hline cnt. & 0.11 & {$[0.000]$} & cnt. & 0.13 & {$[0.000]$} \\
\hline$r_{t}^{e u r 12}$ & -0.76 & {$[0.000]$} & $r_{t}^{g o v}$ & -0.94 & {$[0.001]$} \\
\hline $\operatorname{ogap}_{t}$ & 0.71 & {$[0.000]$} & $\operatorname{ogap}_{t}$ & 0.24 & {$[0.091]$} \\
\hline $\bar{r}^{2}$ & & 0.969 & & & 0.950 \\
\hline s.e. & & 0.004 & & & 0.006 \\
\hline$n$ & & 10 & & & 10 \\
\hline
\end{tabular}

Figure 13 exhibits the actual and fitted patterns of the construction employment share in those key years of the housing bubble. The drop is quite remarkable after 2007 and the fit quite good for both equations in spite of the few observations involved. In the next few paragraphs we will be using the estimated model to assess the contribution of the exogenous variables to the drop in the construction share. 
Figure 13: Construction jobs share

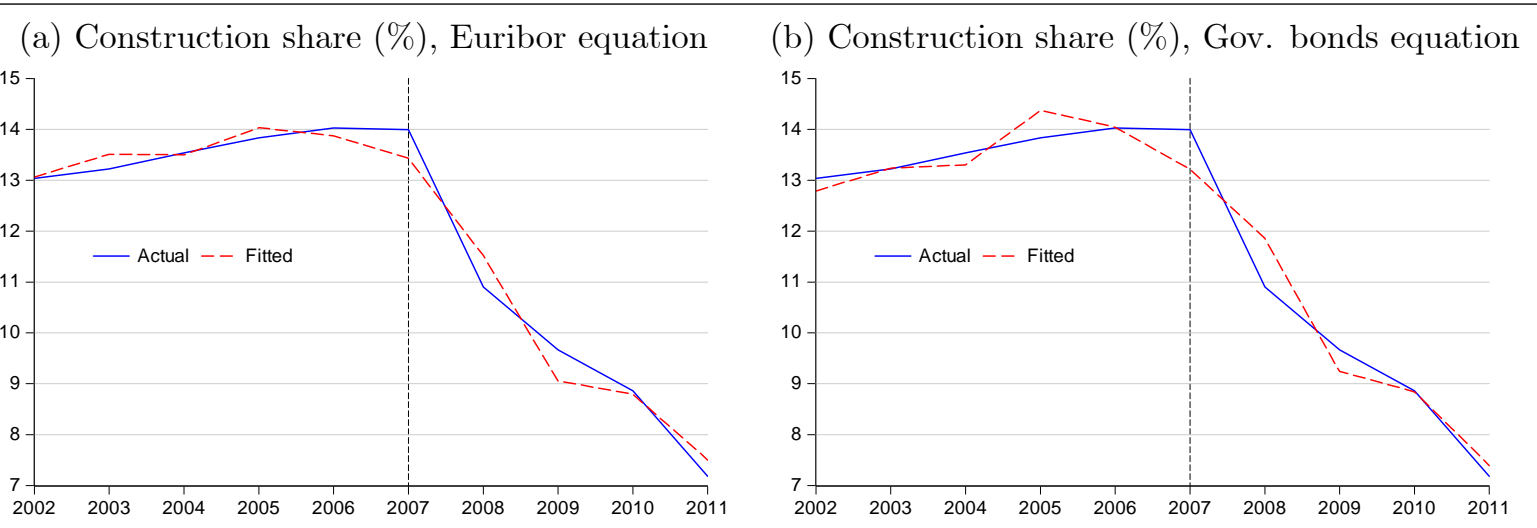

Figure 14 reveals the contributions of the real interest rates in both equations to the drop in construction employment. In both cases the contribution was far from negligible, especially for the rate on government bonds. Respectively, these contributions amount to 1.8 p.p. and 5.1 p.p. for equations in panels (a) and (b).

\section{Figure 14: Contribution of interest rates to the construction share}

(a) Construction share (\%), Euribor equation

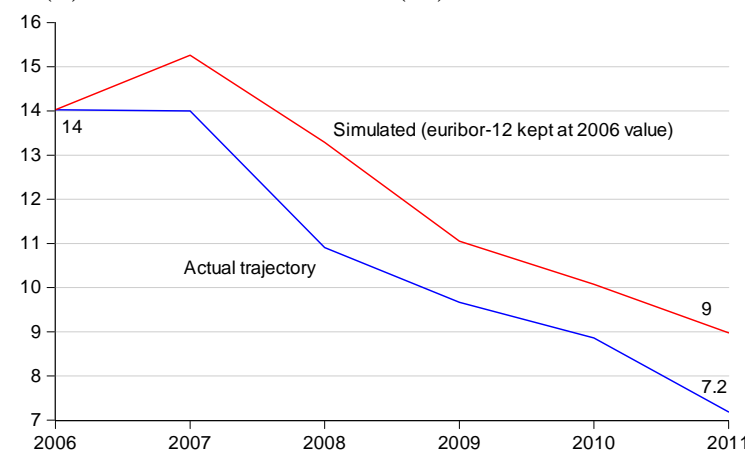

(b) Construction share (\%), Gov. bonds equation

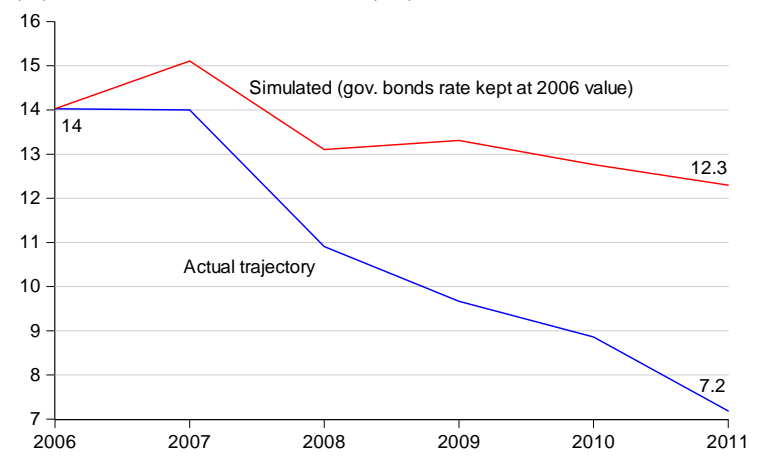

Figure 15 shows the actual and simulated trajectories of the interest rates under consideration. Notice that, for practical reasons, the simulations had to be run starting in 2006 - right during the time when the change in the interest rates was clearly observed, going from negative in 2006 to positive in 2007 for both rates. 
Figure 15: Interest rates, actual and simulated

(a) Euribor-12 (\%)

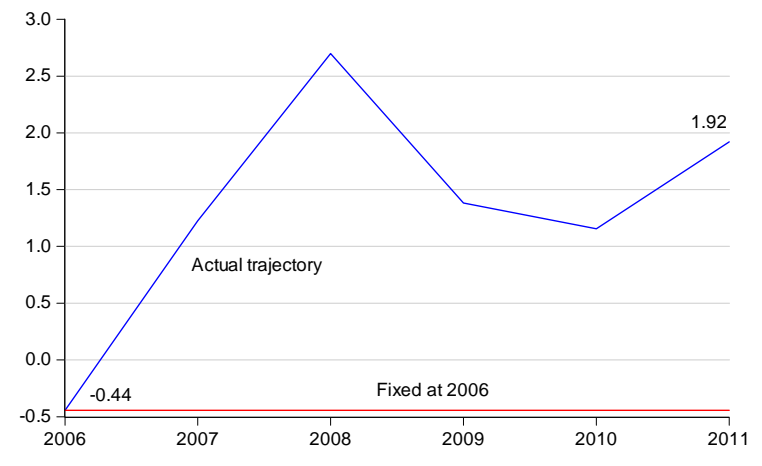

(b) Gov. bonds rate (\%)

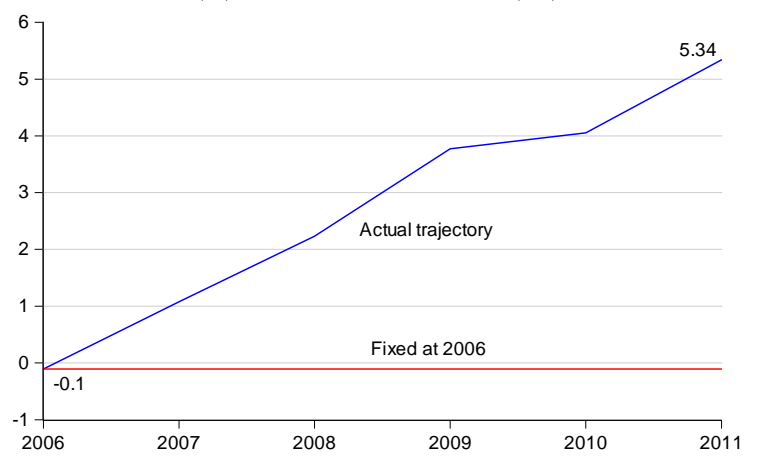

The size of the contributions is switched for the next simulation, where we assess the effect of economic overheating by way of the output gap on the construction share. While the output gap for the Euribor equation in panel (a) of Figure 16 shows a contribution of 5.4 p.p. in the drop of the employment share, the contribution for the government bonds equations in (b) stands at 1.8 p.p..

\section{Figure 16: Contribution of other factors to the construction share}

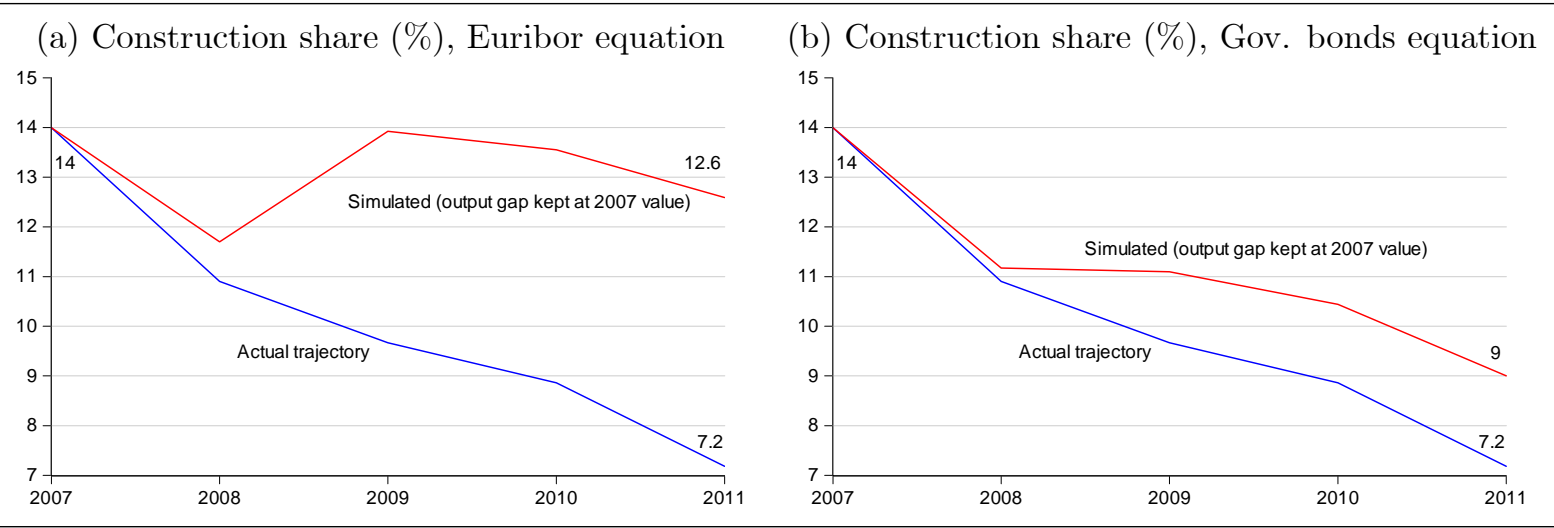

Further notice that if we add both contributions in each one of the equations they roughly add to the total drop in employment - which was approximately of the order of 7 p.p. between 2006-7 and 2011, as seen in Figure 13 above. These numbers are not trivial since total employment in Spain went down by 2.2 millions during that period and the employment in the construction industry shrank by 1.5 millions from almost 3 millions - or a 50\% drop. Finally, Figure 17 shows the actual and simulated trajectory of the output gap for both equations. 


\section{Figure 17: Output gap, actual and simulated}

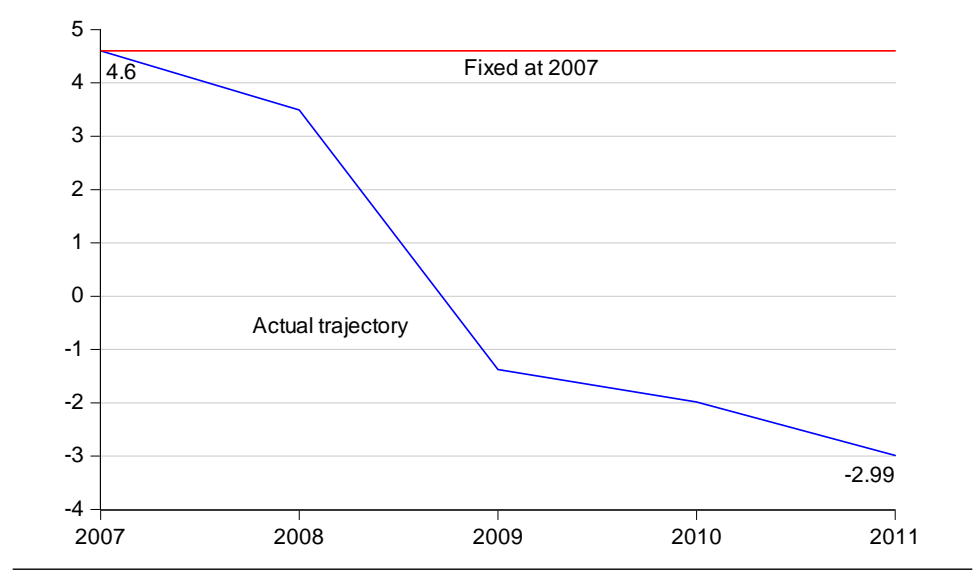

\section{$5 \quad$ Final remarks}

In this paper we have tried to account for the structural change that is currently underway in Spain after the burst of the housing bubble of prior years. For this we have made use of the theoretical framework in Albrecht and Vroman (2002) and have discussed, in broad terms, the different possible equilibria that might occur. We have used France as a yardstick as both countries stood virtually on the same spot at the peak of the bubble in Spain. This meant an 8.5\% of unemployment in 2006 in both countries - something unheard of until then for the Spanish economy. It is worth noting that at the time of the bubble high GDP growth rates coincided with very low productivity growth rates, leading us to reinforce the sense of a strong misallocation of resources and the illusion of wealth.

Our calibrations seem to point to a significant switch, or rather a "jump", between equilibria in Spain and not in France. Allowing for a small productivity gap (case 1 above) between high and low-skill workers suggests that, while the French economy would immediately transition from a CSM to an EPS as soon as the gap becomes wider and at an stable unemployment rate, the Spanish one would remain at an CSM for longer just to jump sharply after a while to a higher unemployment plateau. In order to achieve the peak of the unemployment rate in Spain at $u^{E S P} \approx 0.26$ the productivity of low-skill workers must decrease by about $15 \%$. Allowing now for a big productivity gap (case 2) strengthens our claim that Spain must have necessarily undergone a notable switch or jump between equilibria as the economy starts now at an EPS and at a relatively high unemployment rate $(14 \%)$. Achieving the $u^{E S P} \approx 0.26$ target requires now a drop in low-skill productivity of around 13\%. All in all, and regardless of the initial productivity gap in both countries, the Spanish economy necessitates a bigger gap than France to replicate its actual rate of unemployment-something very much in line with the idea of strong insider-outsider mechanisms and a conspicuous two-tier 
labor market in Spain. Arguably, Spain has jumped from a CSM to an EPS in the post-bubble years while France has either smoothly transitioned from one to the other (case 1) or, more likely, has always been at an EPS (case 2).

To complement our previous analysis we have carried out two sets of counterfactuals exercises descriptive of the Spanish labor market and of the Spanish bubble episode. The first results are indicative of a move in the good direction by the Spanish government, which has however fallen short of achieving a major change for the better-flexibilization has brought Spanish unemployment down but there is still a long way to go. The second results stress the misdirection of resources into the construction industry that were mainly fueled by very low (even negative) real interest rates for the most part of the last decade. We get to explain the whole change in the construction jobs share by way of the real interest rate and the output gap - the latter being broadly identified with additional factors pointing in the direction of economic overheating.

\section{References}

[1] Albrecht, James and Vroman, Susan, 2002. A Matching Model with Endogenous Skill Requirements, International Economic Review 43 (1), 283-305.

[2] Banco de España, 2014. Annual Report 2013, Madrid, ISSN: 1579 - 8623 (online edition).

[3] Bentolila, Samuel, Cahuc, Pierre, Dolado, Juan J., and Le Barbanchon, Thomas, 2012a. Two-Tier Labour Markets in the Great Recession: France Versus Spain, The Economic Journal 122 (562), 155-187.

[4] Bentolila, Samuel, Dolado, Juan J., and Jimeno, Juan F., 2012b. Reforming an insider-outsider labor market: The Spanish experience, IZA Journal of European Labor Studies 1:4.

[5] Bordo, Michael D. and Landon-Lane, John, 2013. Does Expansionary Monetary Policy Cause Asset Price Booms: Some Historical and Empirical Evidence, NBER Working Paper No. 19585.

[6] Calvo, Guillermo, 2013. Puzzling over the Anatomy of Crises: Liquidity and the Veil of Finance, Bank of Japan IMES Discussion Paper 13-E-09.

[7] Davidson, Carl, Matusz, J. Steven, and Shevchenko, Andrei, 2008. Outsourcing Peter to pay Paul: High-skill Expectations and Low-skill Wages with Imperfect Labor Markets, Macroeconomic Dynamics 12 (4), 463-479. 
[8] Estrada, Angel, Hernando, Ignacio and López-Salido, J. David, 2000. Measuring the NAIRU in the Spanish Economy, Banco de España Working Papers \#0009.

[9] Garriga, Carlos, 2010. The role of construction in the housing boom and bust in Spain. FEDEA Working Papers 2010-09.

[10] Hayek, Friedrich A. von, 1931, reprint 2008. Prices and Production and Other Works On Money, the Business Cycle, and the Gold Standard, Auburn, AL: Ludwig von Mises Institute.

[11] IMF (various authors), 2008. Competitiveness in the Southern Euro Area: France, Greece, Italy, Portugal, and Spain, IMF WP 08/112.

[12] Lindbeck, Assar and Snower, Dennis, 1988. The Insider-Outsider Theory of Employment and Unemployment, MIT Press.

[13] McKinsey\&Company-Fedea (various authors), 2010. A Growth Agenda for Spain.

[14] Mc Morrow, Kieran and Roeger, W., 2000. Time-Varying NAIRU/NAWRU Estimates for the EU's Member States, ECFIN Economic Paper No. 145.

[15] Miao, Jianjun, and Wang, Pengfei, 2012. Bubbles and Total Factor Productivity, American Economic Review 102 (3), 82-87.

[16] Mises, Ludwig von, 1912, reprint 1981. The Theory of Money and Credit, Indianapolis, IN: Liberty Fund.

[17] OECD Economic Surveys Spain (various authors), 2005, 2014. ISSN 0376-6438.

[18] OECD Report (various authors), 2007. Staying Competitive in the Global Economy: Moving Up the Value Chain, OECD Publishing ISBN 9264034250.

[19] Ventura, Jaume, 2002. Bubbles and Capital Flows, NBER Working Papers 9304. 


\section{A Appendix: Data sources}

Table A: Data sources

Real GDP growth (\%)

Unemployment rate (\%)

Construction jobs

Mortgages

Real long-term interest on gov. bonds (\%)

Real Euribor-12 months (\%)

Labor productivity, growth rate (\%)

Unit labor costs, growth rate (\%)

Output gap (\%)

Total and self-employment data
OECD Economic Outlook 96 (2014).

OECD Economic Outlook 96 (2014). EUROSTAT and INE (2015).

INE (2015).

OECD Economic Outlook 96 (2014).

Bank of Spain (2015).

OECD Economic Outlook 96 (2014).

OECD Economic Outlook 96 (2014).

OECD Economic Outlook 96 (2014).

OECD Economic Outlook 96 (2014).

Note: Both real interest rates deflated by gross domestic product deflator, market prices (OECD).

\section{B Appendix: CMS and EPS equations}

We outline all the equations that must hold in CSM and EPS equilibria.

Cross-skill matching equilibrium:

Bellman equations of employed workers are

$$
\begin{aligned}
r W_{L} & =w_{L}-\delta\left(W_{L}-U_{L}\right), \\
r W_{L(H)} & =w_{L(H)}-\delta\left[W_{L(H)}-U_{H}\right] \\
r W_{H} & =w_{H}-\delta\left(W_{H}-U_{H}\right) .
\end{aligned}
$$

Bellman equations that characterize the unemployed workers are

$$
\begin{aligned}
r U_{L} & =b+\phi m(\theta)\left(W_{L}-U_{L}\right) \\
r U_{H} & =b+m(\theta)\left[\phi W_{L(H)}+(1-\phi) W_{H}-U_{H}\right]
\end{aligned}
$$

Bellman equations for the active firms are

$$
\begin{aligned}
r J_{L} & =\left(y_{L}-w_{L}-c\right)-\delta\left(J_{L}-V_{L}\right), \\
r J_{L(H)} & =\left[y_{L(H)}-w_{L(H)}-c\right]-\delta\left[J_{L(H)}-V_{L}\right], \\
r J_{H} & =\left(y_{H}-w_{H}-c\right)-\delta\left(J_{H}-V_{H}\right) .
\end{aligned}
$$


Corresponding equations for inactive firms are

$$
\begin{aligned}
& r V_{L}=-c+z(\theta)\left[\gamma J_{L}+(1-\gamma) J_{L(H)}-V_{L}\right] \\
& r V_{H}=-c+z(\theta)(1-\gamma)\left(J_{H}-V_{H}\right) .
\end{aligned}
$$

Wages are set in the Nash bargaining process as

$$
\begin{aligned}
w_{L} & =\beta\left(y_{L}-c\right)+(1-\beta) r U_{L}, \\
w_{L(H)} & =\beta\left(y_{L}-c\right)+(1-\beta) r U_{H}, \\
w_{H} & =\beta\left(y_{H}-c\right)+(1-\beta) r U_{H} .
\end{aligned}
$$

Zero vacancy conditions, $V_{L}=V_{H}=0,(1)$ and (2) must also hold. Cross-skill matching equilibrium will exist if

$$
y_{L}-c>r U_{H}
$$

\section{Ex-post segmentation equilibrium:}

Bellman equations that characterize the employed workers are (3) and (5), corresponding equations for unemployed workers are (6) and

$$
r U_{H}=b+(1-\phi) m(\theta)\left(W_{H}-U_{H}\right) .
$$

Bellman equations for the active firms are (8) and (10), and for the inactive firms are

$$
r V_{L}=-c+z(\theta) \gamma\left(J_{L}-V_{L}\right)
$$

and (12). ${ }^{15}$ Zero vacancy conditions, $V_{L}=V_{H}=0,(1)$ and (2) must also hold. The condition for the existence of the EPS equilibrium implies that high-skill workers are matching only with high-skill jobs

$$
y_{L}-c \leq r U_{H}
$$

\footnotetext{
${ }^{15}$ Notice that equations (17) and (18) now imply that high-skill unemployed workers will only take high-skill jobs and low-skill firms will ony hire low-skill workers.
} 